\title{
Saudação À Professora Angelita Habr-Gama, EM SUA POSSE COMo Honorária Nacional da Academia Nacional de Medicina,
} EM O4 DE NOVEMBRO DE 202 I

\section{Eduardo Lopes Pontes}

Membro Titular, Academia Nacional de Medicina

Ilmo Sr. Presidente daANM, Acadêmico Rubens Belfort, Senhoras Acadêmicas e Senhores Acadêmicos, Sras. e Srs.

Hoje, a Academia Nacional de Medicina dá um importante passo ao receber como Membro Honorário a Profa. Angelita Habr-Gama, no encerramento do Simpósio Mulheres Médicas que Inspiram.

Sua trajetória, caracterizada pelo pioneirismo, tenacidade e perseverança derrubou obstáculos que viriam abrir portas para as futuras geraçóes de médicas por todo o país inspiradas pelo seu exemplo.

Nascida na Ilha de Marajó, Pará, aos dois anos com a família mudou-se para São Paulo, onde aos 19 anos, entra na faculdade de medicina da USP. Ao final do curso consegue a posição de residente de cirurgia no hospital de clínicas, sendo a primeira mulher a obter

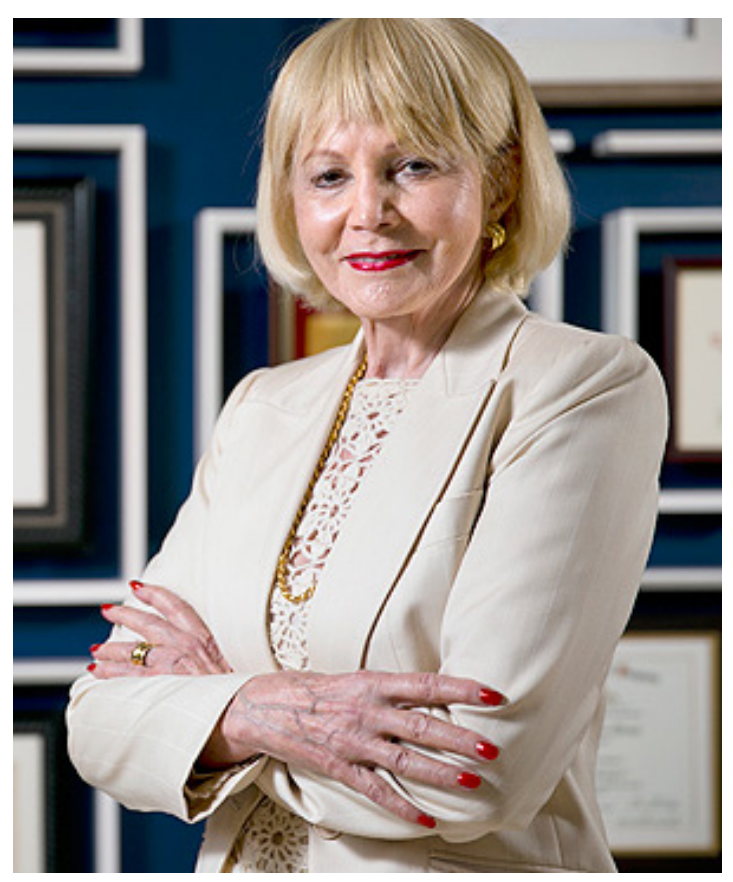

Professora Angelita Habr-Gama 
tal posto ao longo de sua extensa e profícua carreira, chegando ao cargo de professora titular de cirurgia da FMUSP. Desenvolveu ilhas de pesquisa: Câncer colorretal, diagnóstico, estadiamento, prognóstico e tratamento de doenças inflamatórias do intestino grosso, doenças de chagas, fisiologia anorretal e incontinência anal, constipação intestinal essencial, cirurgia laparoscópica, colonoscopia e insuficiência intestinal grave.

Tornou-se uma das mais renomadas cirurgiãs da história da medicina brasileira e uma referência mundial. Foi presidente do Colégio Brasileiro de Cirurgia Digestiva. Indicada pela Organização Mundial de Gastroenterologia (OMGE) como coordenadora no Brasil do Programa de Prevenção do Câncer Colorretal. Fundou e preside a Associação Brasileira de Prevenção do Câncer de Intestino (ABRAPRECI).

- Foi a primeira mulher a se tornar Membro Honorário da Centenária Sociedade Científica American Surgical Association desde 2002.

- Conquistou o prêmio mulheres mais influentes FORBES BRASIL 2006. Foi escolhida entre três mulheres selecionadas para a categoria. Primeiro médico latino-americano e a primeira mulher a integrar o seleto grupo de 17 membros Honorários da European Surgical Association em 2006.
- É membro Honorário das seguintes sociedades científicas:

- American Surgical Association

- American College of Surgeons

- American Society of Colon and Rectal Surgeons

- Royal College of Surgeons of England

- Colégio Brasileiro de Cirurgióes

- European Society of Coloproctology

- Publicou 243 artigos científicos em revista indexadas no PUBMED

- Fundou a ABRAPECI - Associação Brasileira de Prevençáo do Câncer de Intestino

- Medalha Santos Dumont

- Medalha do Pacificador

- Medalha do Hospital Naval

- Grau de Grã-Cruz da Ordem do Ipiranga

- Prêmio Mulheres mais influentes FORBES BRASIL 2006

- Troféu Guerreiro da Educação

- Medalha Institucional do Centenário da Faculdade de Medicina da USP

- Prêmio "Society's Robert W. Beart, MD the Impact Paper of the Year Award" da American Society of Colon and Rectal Surgeons pelo Artigo "Watch and Wait Approach Following Extended Neoadjuvant Chemoradiation for distal Rectal Cancer: Are We Getting Closer to Anal Cancer Management?" Publicado pela Revista Diseases of the 
Colon and Rectum (Dis Colon Rectum 2013; 56:1109-17) outorgado durante o Congresso da Sociedade em Hollywood, Flórida, maio de 2014.

- Professora Visitante na Universidade de Harvard e Johns Hopkins em 2015

- Título de Cidadã Paulistana

Em março de 2002, no Guarujá em São Paulo, ocorreu a criação do grupo de estudos em doenças inflamatórias intestinais do Brasil. Criação esta que a professora Angelita e eu participamos como Membros fundadores.
Nesta ocasião, estreitamos nossos laços e tive a oportunidade de conhecer e admirar suas qualidades humanas e profissionais, tais como sua dedicação à Ciência e, principalmente, aos doentes por ela tratados.

Neste momento histórico, de pandemia, que ressaltou para a sociedade como um todo a importância do conhecimento médico-científico, a Academia Nacional de Medicina tem a honra de receber esta cientista proeminente e vanguardista, que certamente elevará ainda mais o nível de nosso convívio e muito contribuirá para as funçôes e expectativa científicas desta casa. Seja bem-vinda, Professora Dra. Angelita Habr-Gama. 